\author{
Review Article \\ www.ijrap.net (ISSN:2229-3566)
}

\title{
A CRITICAL REVIEW ON BHASMA AND NANOMEDICINE
}

\author{
Rahul Yashavanth *1, Mrudula K. S ${ }^{2}$ \\ ${ }^{1}$ Assistant Professor, Department of Rasa Shastra Evam Bhaishajya Kalpana, Yenepoya Ayurveda Medical College, \\ Naringana, Mangalore, Karnataka, India \\ ${ }^{2}$ Assistant Professor, Department of Prasooti Tantra Evam Stree Roga, Yenepoya Ayurveda Medical College, \\ Naringana, Mangalore, Karnataka, India
}

Received on: 21/04/20 Accepted on: 26/05/20

\author{
*Corresponding author \\ E-mail: rahulyashavanth@gmail.com
}

DOI: $10.7897 / 2277-4343.1104116$

\begin{abstract}
The metals and minerals by the virtue of their nature are heavy, non-assimilable and toxic in their original form, though toxic in nature they were used in therapeutics since the time of Veda. After the development of shodhana (purifying process) and marana (process of making bhasma) techniques, the utility of metals and minerals in medicine increased to three folds as it converts them to micro fine and assimilable form i.e. bhasma, with no toxic effects when prepared and used judiciously. The bhasma when analysed for its particle size, mostly falls under the range of nanoparticles. Nano medicine is an offshoot of nanotechnology, the size of which falls in between $1 \mathrm{~nm}-100 \mathrm{~nm}$. Considerable amount of research has been conducted in this field to analyse the use of Nanomedicine in healthcare sector. Because of their minute size, they can easily target difficult to reach sites with improved solubility and bioavailability. They also pose potential risks for the human health and the environment. The Nano medicine possesses various pros and cons, whereas the bhasma when used judiciously can be superior to Nano medicine in the treatment of diseases due to its limited toxicity and high efficiency.
\end{abstract}

Keywords: Nanotechnology, Nanomedicine, Nanoparticle Bhasma, Shodhana, Marana.

\section{INTRODUCTION}

The bhasma is therapeutically the most effective and least or nontoxic form of medicines incorporated into the main streamline with the development of shodhana and marana techniques, respectively. Before the development of marana, fine powder of metals was used in therapeutics during the Samhita kala $\left(1^{\text {st }}-4^{\text {th }}\right.$ century) termed as Ayaskuthi. The size of bhasma ranges mostly in nanometres; which results from a particular metal / mineral undergoing a repeated number of shodhana and marana process. Size reduction plays a key important factor in determining the efficacy of the bhasma. Owing to its minuscule size, the bhasma is easily ingested into the body, which makes it highly potent even in a small dose. ${ }^{1}$

An offshoot of nanotechnology, the term Nano medicine first emerged in the year 1999 and since then it has gained interest at a global level for research and development. Nano medicine is defined as the science and technology of diagnosing, treating and preventing disease and traumatic injuries, relieving pain and improving human health using molecular tools and molecular knowledge of human body. ${ }^{2}$ In Nano medicine, the particle size ranging in between $1-100 \mathrm{~nm}$ is studied. ${ }^{3}$ Speciality of the nanoparticle is their size. Reducing the size of the particle increases the individual surface area, which helps in potentiating the medicine.

\section{Types of Nanoparticles and their biomedical applications}

Nanoparticles are classified into the following types based on the materials used for the preparation of these particles.

\section{Polymer}

Consists of nanoparticles prepared out of natural or synthetic polymers such as albumin, polyethylene glycol etc.

\section{Carbon}

They belong to fullerenes, structures made exclusively of carbon.

\section{Quantum dots}

Semi conducting nanocrystals with diameter from $2 \mathrm{~nm}-10 \mathrm{~nm}$; it consists of metalloid crystalline core wrapped in a semiconductor shell.

\section{Ceramic}

Prepared from inorganic materials such as silica, aluminia and Titania etc

\section{Lipid}

Usually found in the form of a sphere which comprises of a lipid layer surrounding the drug.

\section{Metal}

They are extremely small $(\sim 50 \mathrm{~nm})$ and are made up of different metals such as gold, silver, nickel, titanium etc. 


\section{Magnet}

Magnetic nanoparticles are the one which can be manipulated using an external magnetic field. Iron oxide (II) is the commonly used under this category.

\section{Solid}

They are also known as Solid Lipid nanoparticles, they are made up of lipids which are solid at room and body temperature.

\section{Viral}

Virus extracted from bacteria and plant origin is usually used as nanoparticles as they are less likely to be pathogenic to humans.

The above mentioned types of nanoparticles are used in diagnostics such as image contrast agents and biomarkers and in disease therapy such as drug delivery, gene therapy and photo dynamic therapy. (Figure 1$)^{4}$

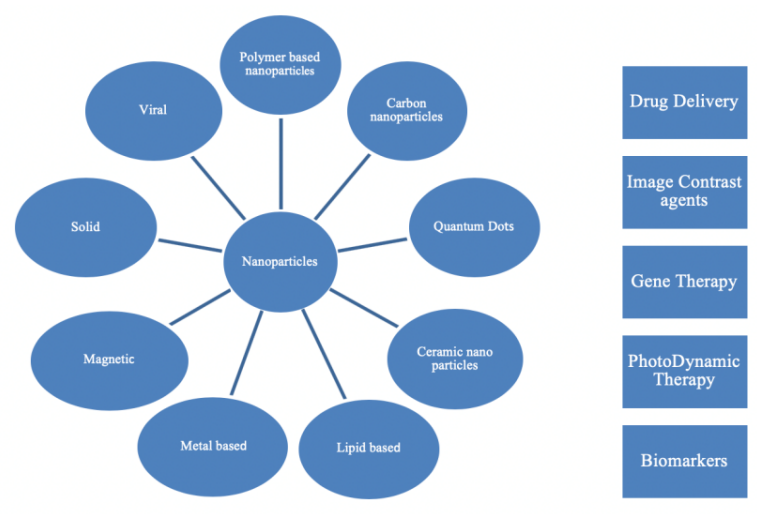

Figure 1: Types of Nanoparticles and their Biomedical Applications

\section{Importance of Nano medicine}

- Requires less quantity of drug- The drug acts precisely on the specified site, hence it can achieve the same therapeutic effect using a smaller dose than their current counterparts.

- Efficient drug release- Nano materials comprises of different materials such as lipid, polymer, metal, ceramic etc. which helps in efficient drug release based on the various sites of the body in which the drug needs to be released.

- Target specificity-Engineered nano materials or carriers can be specifically guided to a target from a source outside the body.

- Carry high concentration of drug-Owing to the high surfacearea-to-volume ratio, the nanoparticles can carry a high concentration of drug.

- Reduction in systemic side effects of the drug-The drug is directly guided to the target site, bypassing the first phase metabolism, reducing the systemic side effects. ${ }^{5}$

\section{Toxicity issues}

Nanomaterials can lead to biological and environmental toxicity Exposure of the nanomaterials to the body may produce inflammation, immunotoxicity, carcinogenicity, etc. During the development of the Nano medicine, researchers do not test the potential toxic outcomes of nanoparticles which lead to its potential toxicity. E.g. In vitro studies on toxicity of gold nanoparticles have shown that they could induce apoptosis and necrosis in different cell types. ${ }^{6}$

In the recent years various studies on the engineered nanoparticles have shown the outcomes in the form of genotoxicity and carcinogenicity. The nanoparticles excreted from the body would mostly be disposed in air and water. The nanoparticles could be suspended in air for a longer period because of their small size, which can cause respiratory disorders in other people inhaling it. ${ }^{7}$

\section{Ethical issues}

The booming advancements in nanotechnology have made the government to actively address the ethical, social and regulatory aspects of nanotechnology and develop judicial policies to prevent its detrimental impacts on the environment and public health. Before commercialization of Nano medicine they must undergo extensive pre-clinical and clinical testing.

All clinical investigations must maintain a data and safety monitoring board (DSMB) to minimize any potential damage to human subjects and also conduct long term follow-ups and assessments to monitor the safety of Nanomedicine. ${ }^{8}$ There is need for a patent law at international level to promote global justice and fair pricing scheme irrespective of the cast and creed. ${ }^{9}$

\section{Influence of Shodhana and Marana in preparing Bhasma}

Bhasma is metallic / mineral complex is with improved stability, functionality and effectiveness. Shodhana helps in the following ways. $^{10}$

- Disintegrating the drug and reducing its particle size along with removal / neutralizing of toxic materials present in the drug and inducing therapeutic properties in the drug.

- Helps in exposing the maximum surface area of the drug for chemical /physical reaction.

- Helps in reducing the hardness and makes the drug brittle.

Marana helps in the following ways ${ }^{11}$

- Disintegrating the drug.

- Conjugation of trace elements.

- Elimination of impurities present in the drug after the shodhana.

- Formation of compounds favourable to the body.

\section{Common properties of Bhasma and Nano medicine}

- Targeted drug delivery

- Reduced particle size

- Small dosage

- Fast acting

- Easy absorption and assimilation.

- Acts at a cellular level.

\section{Speciality of size reduction in Bhasma and Nano medicine}

By reducing the size, the surface-area-to-volume ratio increases by $10^{9}$. This leads to an increase in the dominance of quantum effects, thus one can achieve a wide range of properties in a drug by reducing the particle size. ${ }^{12}$ 


\section{Pros and Cons of Nanomedicine}

\section{Pros}

- Drug delivery to the exact location.

- Less side effects

- Molecular targeting by engineered Nano devices.

- Less quantity of drug required

- Surgery can be avoided.

\section{Cons}

- Not cost effective

- Ethical clearance

- Environment toxicity

- Implementation difficulties ${ }^{13}$

Superiority of Bhasma over Nanomedicine of Contemporary science

- Potent in a small dose.

- No specific taste.

- Cost effective.

- No implementation difficulties.

- Multi action drug.

- No toxicity issues when prescribed in therapeutic dose.

- Can be manufactured with minimum setup facilities.

\section{CONCLUSION}

Nano medicine has shown a great potential to address clinical needs in various diseases. There are varieties of engineered nanoparticles which have been studied and proved efficacious in the treatment of various diseases. However, toxicity and ethica issues of Nano medicine are of particular concern; whereas, bhasma are effective, safe, non- toxic when prepared and used judiciously. It is the need of the hour for us to convey the safety, non-toxicity of the bhasma among the practitioners and its utility in various diseases, to make them more effective in serving the society.

\section{REFERENCES}

1. Ravindra Angadi. Rasa Shastra: Itihasa Evam Kramika Vikasa. A text book of Rasa Shastra. First edition. Varanasi: Chaukhambha Surabharati Prakashan; 2014. p. 11.

2. Prabala Balakrishna, Jain Dharmendra: Ethical issues in nanomedicine. The Holistic Approach to Environment 2012; (Cited 2020 Mar 5) 4: 171-175. Available from: https://www.semanticscholar.org/paper/ETHICAL-ISSUESIN-NANO MEDICINE-Prabhala-Dharmendra/9413843d 301c11ffae389fe2319d578a7742e8b7

3. S. Kulkarni, Santosh. Bhasma and Nanomedicine. International Research Journal of Pharmacy 2013; (Cited 2020 Feb 26) 4: 10-16. Available from: https://www.researchgate.net/publication/307784319BHASMA-AND-NANO-MEDICINE.
4. Shivani Soni, Amandeep Salhotra, Mrutyunjay Suar. Nanomedicine: Therapeutic Applications and Limitations. Handbook of Research on Diverse Applications of Nanotechnology in Biomedicine, Chemistry and Engineering. Reprint edition. USA: IGI Global; 2014. p. 6478.

5. Shivani Soni, Amandeep Salhotra, Mrutyunjay Suar. Nanomedicine: Therapeutic Applications and Limitations. Handbook of Research on Diverse Applications of Nanotechnology in Biomedicine, Chemistry and Engineering. Reprint edition. USA: IGI Global; 2014. p. 6478.

6. Shivani Soni, Amandeep Salhotra, Mrutyunjay Suar. Nanomedicine: Therapeutic Applications and Limitations. Handbook of Research on Diverse Applications of Nanotechnology in Biomedicine, Chemistry and Engineering. Reprint edition. USA: IGI Global; 2014. p. 6478.

7. Prabala Balakrishna, Jain Dharmendra: Ethical issues in nanomedicine. The Holistic Approach to Environment 2012; (Cited 2020 Mar 5); 4: 171-175. Available from: https://www.semanticscholar.org/paper/ETHICAL-ISSUESIN-NANO MEDICINE-Prabhala-Dharmendra/9413843d301 c11ffae389fe2319d578a7742e8b7

8. Shivani Soni, Amandeep Salhotra, Mrutyunjay Suar. Handbook of Research on Diverse Applications of Nanotechnology in Biomedicine, Chemistry and Engineering. Reprint edition. USA: IGI Global; 2014. p. 78.

9. Prabala Balakrishna, Jain Dharmendra: Ethical issues in nanomedicine. The Holistic Approach to Environment 2012; (Cited 2020 Mar 5) 4: 171-175. Available from: https://www.semanticscholar.org/paper/ETHICAL-ISSUESIN-NANO MEDICINE-Prabhala-Dharmendra/9413843d301 c11ffae389fe2319d578a7742e8b7

10. Ravindra Angadi. Paribhasha Prakarana. A text book of Rasa Shastra. First edition. Varanasi: Chaukhambha Surabharati Prakashan; 2014. p. 24.

11. Ravindra Angadi. Paribhasha Prakarana. A text book of Rasa Shastra. First edition. Varanasi: Chaukhambha Surabharati Prakashan; 2014. p. 24.

12. S. Kulkarni, Santosh. Bhasma and Nanomedicine. International Research Journal of Pharmacy 2013; (Cited 2020 Feb 26) 4: 10-16. Available from https://www.researchgate.net/publication/307784319BHASMA-AND-NANO-MEDICINE.

13. Shivani Soni, Amandeep Salhotra, Mrutyunjay Suar. Nanomedicine: Therapeutic Applications and Limitations. Handbook of Research on Diverse Applications of Nanotechnology in Biomedicine, Chemistry and Engineering. Reprint edition. USA: IGI Global; 2014. p. 6478.

\section{Cite this article as:}

Rahul Yashavanth and Mrudula K. S. A Critical Review on Bhasma and Nanomedicine. Int. J. Res. Ayurveda Pharm. 2020;11(4):201-203 http://dx.doi.org/10.7897/2277$\underline{4343.1104116}$ 